\title{
Analysis of the clonal relationships between strains of Neisseria meningitidis by pulsed field gel electrophoresis
}

\author{
Jane A. Bygraves and Martin C. J. Maiden* \\ Division of Bacteriology, National Institute for Biological Standards and Control, Blanche Lane, Potters Bar, \\ Herts EN6 3QG, UK
}

(Received 5 September 1991; revised 5 November 1991; accepted 19 November 1991)

\begin{abstract}
Fingerprint patterns were generated from strains of Neisseria meningitidis by digestion of chromosomal DNA samples with 'rare-site' restriction endonucleases and resolution of the resultant fragments by pulsed field gel electrophoresis (PFGE). The potential of this technique for the rapid establishment of the clonal relationships between different isolates of the meningococcus was investigated. The fingerprint patterns from various serogroup A strains, previously assigned to clonal subgroups on the basis of their electrophoretic types (ETs), were compared. Fingerprints generated with the endonucleases $S f i \mathrm{I}, \mathrm{SpeI}$ and $\mathrm{NheI}$ each gave distinctive patterns for the clonal subgroups I-IV of serogroup A. Further, the endonucleases $S$ peI and, particularly, NheI were capable of resolving differences between various subgroup III strains isolated at different times and geographical locations. Strains isolated during the 'new wave' pandemic, which was associated with the Haj, from Europe, America, and Africa, had a characteristic fingerprint pattern and appeared to be distinct from 'old wave' pandemic strains. The PFGE technique is a relatively rapid and sensitive method for establishing clonal relationships among epidemic strains of N. meningitidis.
\end{abstract}

\section{Introduction}

Neisseria meningitidis causes bacterial meningitis and septicaemia worldwide (Schwartz et al., 1989). The mechanisms of pathogenicity of this organism are still poorly understood (DeVoe, 1982). In Western Europe and North America the disease occurs endemically as a sporadic disease primarily of infants, young children and adolescents. These cases are most frequently caused by serogroup B or C organisms (Peltola, 1983). In other parts of the world, notably China, the Middle East, and Africa, epidemic outbreaks occur, caused by serogroup A organisms. Although polysaccharide vaccines are available against organisms of the $\mathrm{A}, \mathrm{C}, \mathrm{W}-135$ and $\mathrm{Y}$ serogroups, these are poorly effective in young children (Reingold et al., 1985) and there is no effective vaccine against the group B capsule (Frasch et al., 1988). In recent years there has been considerable interest in the development of new vaccines, particularly against serogroup B organisms (Frasch, 1989). A thorough understanding of the epidemiology and a rapid, precise means of identifying strains are central to the design and implementation of vaccine trials.

* Author for correspondence. Tel. (0707) 54753; fax (0707) 46730
The population genetics of a limited number of bacterial species, mainly pathogens, have been studied, principally by the techniques of multilocus enzyme electrophoresis (MLEE; Selander et al., 1986, 1987). Populations of $N$. meningitidis, in common with those of the other bacteria investigated, have a clonal structure (Caugant et al., 1986, 1987; Olyhoek et al., 1987); that is, isolates of meningococci can be resolved into a limited number of genetically related types, or clones, each thought to contain strains with a common ancestry. The pandemics of serogroup A meningococci are caused by individual clones spreading across continents (Achtman, 1990), sometimes in conjunction with large population movements, for example the Haj (Moore et al., 1989; Achtman, 1990; Jones \& Sutcliffe, 1990; Achtman et al., 1992). These clones are genetically and serologically stable over time, and during intercontinental spread (Crowe et al., 1988, 1989; Achtman, 1990; Salih et al., 1990). The group B and C organisms that cause sporadic, endemic disease are genetically more diverse, particularly the group B meningococci (Caugant et al., 1990); however, single clones of group B organisms are known to have caused epidemic outbreaks, for example the European outbreaks caused by the serogroup B serotype 15 subtype P1.16 strains belonging to the ET-5 cluster (Caugant et al., 1986). 
A number of alternative techniques for the determination of the clonal types present in bacterial populations have been investigated. These have included the analysis of endonuclease digests by conventional agarose gel electrophoresis (Bjorvatn et al., 1984; Olyhoek et al., 1988); restriction fragment length polymorphism (RFLP) types of specific parts of the chromosome (Fox et al., 1991), particularly of ribosomal RNA operons (Stull et al., 1988); and the analysis of bacterial chromosomes by pulsed field gel electrophoresis (PFGE; Schwartz \& Cantor, 1984; Carle et al., 1986) for the analysis of large DNA molecules (Arbeit et al., 1990). In the present work, chromosomal DNA isolated from strains of $N$. meningitidis was digested with restriction endonucleases that cut the chromosome into 10-40 fragments, which were resolved into fingerprint patterns by PFGE. These patterns were produced and interpreted relatively simply and quickly, and were stable for at least eight passages of the strain in vitro. Comparison of these fingerprints was capable of distinguishing and identifying clonal subgroups of meningococcal isolates and of assessing the genetical relationships between strains belonging to the same clonal subgroup.

\section{Methods}

Propagation and maintenance of meningococcal strains. Meningococcal strains were obtained from the United Kingdom Public Health Laboratory Service, the Max-Planck Institut für Molekulare Genetik, Berlin, and the China Committee for the Culture Collection of Microorganisms, as detailed in Table 1 . The strains were maintained at $-70{ }^{\circ} \mathrm{C}$ in a mixture of $50 \%$ Mueller-Hinton broth and $50 \%$ freezing mix' (glycerol, $10 \%$, v/v; sodium citrate, $3 \mathrm{~mm}$; ammonium sulphate, $1 \mathrm{~mm}$; potassium phosphate, $100 \mathrm{mM}, \mathrm{pH} 6.6$ ). Strains were grown at $37^{\circ} \mathrm{C}$ in an atmosphere of $5 \% \mathrm{CO}_{2}$ on heated-blood (chocolate) agar plates for 8-16 h.

Preparation of chromosomal DNA samples. Cells were grown as described above and the growth from five plates was scraped into TE (Tris/ $\mathrm{HCl}, 10 \mathrm{~mm}$; EDTA, $1 \mathrm{mM} ; \mathrm{pH} 8.0 ; 5 \mathrm{ml}$ ). The cell suspension was mixed with an equal volume of melted Sea-Plaque agarose $[1.0 \%$ $(w / v)$ in TE; FMC Bioproducts] at $37^{\circ} \mathrm{C}$. The mixture was directly dispensed into plastic moulds $(0.1 \mathrm{ml}$ capacity; Pharmacia) at ice temperature, and allowed to set. The plugs were removed from the moulds and incubated overnight at $55^{\circ} \mathrm{C}$ in SaET [Sarkosyl, $1 \%(\mathrm{w} / \mathrm{v})$; EDTA, 0.5 M; Tris/HCl, $10 \mathrm{mM} \mathrm{pH} 9.5$ ] with pronase $\mathrm{E}\left(1 \mathrm{mg} \mathrm{ml} \mathrm{m}^{-1}\right.$; Sigma). They were then washed twice at room temperature in SaET without pronase $\mathrm{E}$. The plugs could be stored in this buffer at $4^{\circ} \mathrm{C}$ for at least one year. Prior to use, the plugs were washed three times in TE buffer, and then incubated in a restriction buffer appropriate to the endonuclease to be used (New England Biolabs) with preboiled ribonuclease $\mathrm{A}\left(1 \mu \mathrm{g} \mathrm{ml}^{-1}\right.$; Sigma) at $37^{\circ} \mathrm{C}$ for $30 \mathrm{~min}$ and rewashed in the same buffer twice.

Restriction endonuclease digestion and storage of digested DNA. As required, plugs containing chromosomal DNA were equilibrated with appropriate restriction enzyme buffer, as described above, melted at $65^{\circ} \mathrm{C}$ and digested with restriction endonucleases (New England Biolabs) overnight at $37^{\circ} \mathrm{C}$. At the end of the incubation, the reaction was stopped by the addition of stop buffer [Tris-acetate, $20 \mathrm{~mm}$;
EDTA, $0.5 \mathrm{~mm}$; Orange-G marker dye (Sigma) $1 \mu \mathrm{g} \mathrm{ml}^{-1} ; 1 \%$ (w/v) sea plaque agarose] and heating to $65^{\circ} \mathrm{C}$. Samples were either stored at $-20^{\circ} \mathrm{C}$ or loaded on to the gels immediately. Melting the plugs did not cause non-specific degradation of the chromosomal DNA, and facilitated the subsequent manipulation of the samples.

Pulsed field gel electrophoresis. Pulsed field gel electrophoresis was carried out with a Pharmacia 'Pulsaphor' apparatus. The standard conditions were a constant voltage of $160 \mathrm{~V}$ and starting current of $80 \mathrm{~mA}$ : the electrophoresis buffer was maintained at $14^{\circ} \mathrm{C}$ throughout the experiment. An interpolated program was used: $5 \mathrm{~s}$ pulses to $10 \mathrm{~s}$ pulses in $10 \mathrm{~h}$, followed by $10 \mathrm{~s}$ pulses to $30 \mathrm{~s}$ pulses in $8 \mathrm{~h}$, and $30 \mathrm{~s}$ pulses to $40 \mathrm{~s}$ pulses in $4 \mathrm{~h}$. The gel and running buffer was $0.5 \times \mathrm{TBE}$ (Tris-borate, $5 \mathrm{~mm}$; EDTA, $0.5 \mathrm{mM}$; pH 8.0). After electrophoresis, the gels were stained with ethidium bromide, visualized on an ultraviolet light transilluminator and photographed.

Analysis of data. Restriction fragment sizes were calculated by reference to bacteriophage $\lambda$ DNA of known molecular size. The migration distances were transformed by the inverse of their square root. This gave the closest approximation to a linear relationship between migration distance and molecular size for DNA molecules in the range 50-400 kbp separated by the conditions described above: for sizes smaller than $50 \mathrm{kbp}$, a logarithmic transformation of the data was used. The molecular sizes of the chromosomal fragments were estimated by interpolation within the standard curve, assisted by a BASIC computer program. The reproducibility of band sizes was generally good, with band sizes from different gels usually within $5 \%$. The resolution of the technique was limited mainly by the size of the photograph. The sizes and presence of the smaller restriction endonuclease fragments was confirmed by conventional submerged agarose gel electrophoresis as described by Maniatis et al. (1982).

An assessment of the degree of divergence between related fingerprint patterns was obtained by comparing each fingerprint pattern with each related pattern and scoring the number of shared bands. This figure was divided by the mean of the bands present in the two fingerprint patterns to give a number less than or equal to one (for exact pattern matching), to account for the differences in the number of bands between some pairs of fingerprints. The divergence between all possible pairs of fingerprint pattern was calculated and a phenogram constructed, using the average linkage (UPGMA) method of Sokal \& Michener (1958). This gave a graphical representation of the relationships between strains of the same clonal subgroup.

\section{Results}

\section{Pulsed field electrophoresis of meningococcal DNA}

Appropriate parameters for the analysis of meningococcal DNA were established with chromosomal DNA plugs prepared from strain 2053 (Table 1), a $B: 15: P 1.7,16$ organism isolated during an outbreak of meningococcal disease in Stroud, Gloucestershire, UK (Cartwright et al., 1986). Seven restriction endonucleases with 'rare' recognition sequences (NheI; NotI; PacI; $S f i \mathrm{I}$; SpeI; XbaI; and XhoI) were used in preliminary studies. These endonucleases gave patterns of varying complexity. The simplest pattern was obtained with the endonuclease $S f i \mathrm{I}$ : this fingerprint comprised seven bands of between 20 and $600 \mathrm{kbp}$ in size. The most complex fingerprints were those obtained with endo- 
Table 1. Neisseria meningitidis strains used in this work

NIBSC number (used in this work), original strain number, serological and clonal information (if known) are given, together with the geographical source of the isolate. Details of the clonal subgroup type strains (2151-2190) are given in Olyhoek et al. (1987). Strains 2033 and 2225 were the same isolate from different sources. Strains 2183 and 2222 were also from the same original isolate.

\begin{tabular}{|c|c|c|c|c|c|c|c|}
\hline $\begin{array}{l}\text { NIBSC } \\
\text { number }\end{array}$ & $\begin{array}{l}\text { Strain } \\
\text { number }\end{array}$ & Serogroup & $\begin{array}{l}\text { Serotype } \\
\text { /subtype }\end{array}$ & Clone & $\begin{array}{l}\text { Geographical } \\
\text { location of } \\
\text { isolation }\end{array}$ & $\begin{array}{l}\text { Year of } \\
\text { isolation }\end{array}$ & Source \\
\hline 2009 & 10025 & A & & IV-3 & USA & 1937 & NCTC \\
\hline 2002 & 29001 & A & & & & & ССССM \\
\hline 2053 & F126 & B & $15: P 1.16$ & ET-5 & UK & 1986 & PHLS \\
\hline 2033 & H2182 & $\mathbf{A}$ & & & UK & 1987 & PHLS \\
\hline 2034 & H2224 & A & & & UK & 1987 & PHLS \\
\hline 2035 & H2283 & A & & & UK & 1987 & PHLS \\
\hline 2036 & H2360 & A & & & UK & 1987 & PHLS \\
\hline 2037 & H2525 & A & & & UK & 1987 & PHLS \\
\hline 2038 & H2576 & A & & & UK & 1987 & PHLS \\
\hline 2039 & H2591 & A & & & UK & 1987 & PHLS \\
\hline 2040 & J78 & A & & & UK & 1988 & PHLS \\
\hline 2041 & $\mathrm{~J} 117$ & A & & & UK & 1988 & PHLS \\
\hline 2042 & $\mathrm{~J} 126$ & A & & & UK & 1988 & PHLS \\
\hline 2151 & B40 & A & P1.10 & I-1 (ET-1) & Morocco & 1967 & MPIMG \\
\hline 2177 & B534 & A & & II-1 (ET-27) & UK & 1941 & MPIMG \\
\hline 2183 & B54 & $\mathbf{A}$ & P1.9,X & III-1 (ET-34) & Finland & 1975 & MPIMG \\
\hline 2184 & B227 & A & P1.9,5 & III-1 (ET-36) & Denmark & 1974 & MPIMG \\
\hline 2185 & B554 & A & & III-1 (ET-37) & Finland & 1977 & MPIMG \\
\hline 2186 & B515 & A & & III-2 (ET-38) & Finland & 1975 & MPIMG \\
\hline 2187 & B306 & A & & III-3 (ET-39) & Nepal & 1983 & MPIMG \\
\hline 2188 & B503 & A & & III-4 (ET-40) & China & 1984 & MPIMG \\
\hline 2189 & B506 & $\mathbf{A}$ & & III-4 (ET-4I) & Brazil & 1976 & MPIMG \\
\hline 2190 & B48 & A & P1.7 & IV-1 (ET-42) & Gambia & 1983 & MPIMG \\
\hline 2221 & Z4088 & A & & III-1 & China & 1987 & MPIMG \\
\hline 2222 & Z1054 & A & & III-1 & Finland & 1975 & MPIMG \\
\hline 2223 & Z3905 & $\mathbf{A}$ & & III-1 & China & 1966 & MPIMG \\
\hline 2224 & Z3703 & A & & III-1 & Sweden & 1973 & MPIMG \\
\hline 2225 & Z3771 & A & & III-1 & UK & 1987 & MPIMG \\
\hline 2226 & Z3768 & A & & III-1 & Norway & 1969 & MPIMG \\
\hline 2227 & Z3524 & A & & III-1 & Chad & 1988 & MPIMG \\
\hline 2228 & Z3529 & A & & III-1 & Chad & 1988 & MPIMG \\
\hline 2230 & Z3747 & A & & III-1 & Sudan & 1988 & MPIMG \\
\hline 2233 & Z3726 & A & & III-1 & Sweden & 1983 & MPIMG \\
\hline 2236 & Z3696 & A & & III-1 & Sudan & 1988 & MPIMG \\
\hline 2237 & Z3506 & A & & III-1 & USA & 1987 & MPIMG \\
\hline
\end{tabular}

NCTC, National Collection of Type Cultures.

CCCCM, China Committee for the Culture Collection of Micro-organisms.

PHLS, Public Health Laboratory Service, Withington Hospital, Manchester, UK.

MPIMG, Max-Planck Institut für Moleculare Genetik, Berlin, FRG.

nucleases $X h o I$ and $X b a I$ : each of these endonucleases produced more than 30 fragments, the majority between 15 and $50 \mathrm{kbp}$ in size. The restriction endonuclease $N o t \mathrm{I}$ gave 34 fragments ranging between 4 and $130 \mathrm{kbp}$; NheI, 16 fragments between 5 and $400 \mathrm{kbp} ;$ PacI, 14 fragments of 4-400 kbp; and SpeI, 19 fragments of 6-300 kbp. To test the stability of the restriction endonuclease fingerprints obtained, the strain was passaged eight times on heated-blood agar plates and restriction patterns were resolved from DNA isolated from cells of each passage. No changes were observed in any endonuclease fingerprint. The fingerprints obtained with the endonuclease $S f i$ for 16 meningococcal reference strains were com- pared. Each strain included in this analysis had a different fingerprint pattern. The pattern diversity seen in this relatively small sample of strains indicated that the sequence divergence between meningococcal strains was measurable by this technique. Calculations based on these and other data suggested that the meningococcal chromosome was $1.8-2.0 \mathrm{Mbp}$ in size.

\section{Analysis of serogroup A meningococcal reference strains}

Representative serogroup A strains of each of the known clonal subgroups of this serogroup (I-IV; Table 1; 


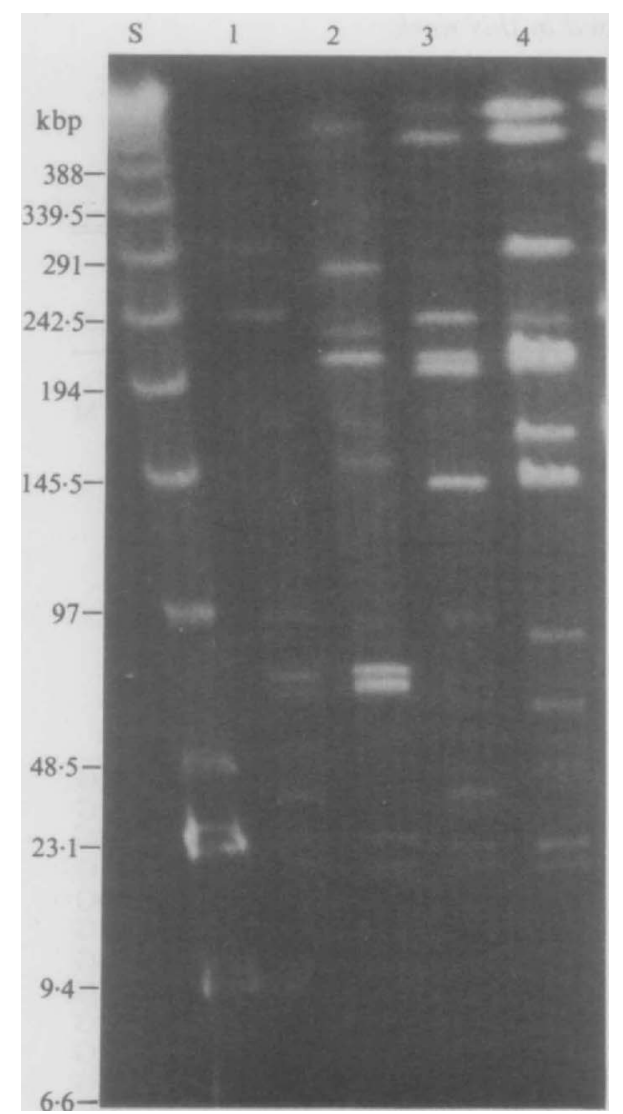

Fig. 1. Restriction endonuclease digestions of chromosomal DNA isolated from serogroup A strains of known clonal type with SfiI resolved into fingerprint patterns by PFGE. Lanes: $S$, standards, i.e. concatamerized phage $\lambda$ DNA mixed with HindIII-digested phage $\lambda$ DNA; lane 1, strain 2151 (clone I-1); lane 2, strain 2177 (clone II-1); lane 3, strain 2183 (clone III-1); lane 4, strain 2190 (clone IV-1). Sizes (kbp) of standard DNA molecules are indicated.

Olyhoek et al., 1988) were analysed with the three restriction endonucleases $S f i I$ (Fig. 1), SpeI (data not shown), and NheI (Fig. 2a). Each of these endonucleases gave fingerprint patterns unique to the clonal subgroups studied, although there was some similarity between the $S f i$ fingerprints of some of the clones.

The diversity of SfiI, SpeI, and NheI restriction fingerprints within a clonal subgroup was assessed by the analysis of seven electrophoretic types of subgroup III (strains 2183-2189; Table 1). These analyses showed that whilst all seven variants had the same $S f i$ I fingerprint pattern (lane 3, Fig. 1), there were minor variations in the SpeI and NheI fingerprints (Fig. 2b). Each of the NheI fingerprint patterns gave a total genome size of between 1.94 and $1.96 \mathrm{Mbp}$ in size, with the exception of strain 2189 , which gave a size of $2 \cdot 12 \mathrm{Mbp}$.
Assessment of genetical relationships within subgroup III by PFGE analysis

An analysis of the $S f_{i I}$ and $N h e I$ fingerprints of 9 group A meningococcal clinical isolates, a NCTC serogroup A reference strain, and a serogroup A strain obtained from the China Committee for the Culture Collection of Micro-organisms, was carried out to determine their clonal relationships and genetical diversity. Three of these strains $(2022,2035,2037)$ had SfiI, SpeI, and NheI fingerprints similar to that of the subgroup I reference strain (Fig. 1, Fig. 2a, and data not shown). The remainder of the strains had $S f i$ I fingerprint patterns similar to the subgroup III strains examined. Further analyses with $N$ heI were consistent with these results, but showed greater pattern diversity, particularly within the 9 strains belonging to subgroup III (Table 3). Similar results were observed with fingerprints generated by SpeI.

Table 2. Restriction endonuclease fragments generated by NheI from $N$. meningitidis strains of clone III

Twenty-seven strains were analysed on three pulsed gels, and the resultant bands measured and assigned. The size of the smallest band (no. 1) was estimated from the same samples analysed on conventional gels. The mean band sizes, standard deviation, and standard error of means of all the bands considered to be equivalent are shown.

\begin{tabular}{|c|c|c|c|c|}
\hline $\begin{array}{c}\text { Band } \\
\text { number }\end{array}$ & $\begin{array}{l}\text { Band size } \\
\text { (kbp) }\end{array}$ & SD & SEM & $\begin{array}{l}\text { Number of bands measured } \\
\text { (number of gels) }\end{array}$ \\
\hline 1 & $5 \cdot 1$ & $0 \cdot 1$ & 0.02 & $27(3)$ \\
\hline 2 & $12 \cdot 3$ & 0.67 & 0.13 & $26(3)$ \\
\hline 3 & 16.5 & & & $1(1)$ \\
\hline 4 & $19 \cdot 1$ & 1.0 & 0.9 & $4(3)$ \\
\hline 5 & $22 \cdot 7$ & 1.7 & 0.3 & $25(3)$ \\
\hline 6 & 37 & $4 \cdot 6$ & 1.4 & $11(3)$ \\
\hline 7 & 44.8 & 3 & $2 \cdot 15$ & $2(2)$ \\
\hline 8 & 49.9 & & & 1 (1) \\
\hline 9 & 57.8 & $3 \cdot 2$ & 0.6 & $26(3)$ \\
\hline 10 & 69.5 & 3 & 0.6 & $26(3)$ \\
\hline 11 & $76 \cdot 2$ & 3.9 & 1.2 & $9(3)$ \\
\hline 12 & 78.8 & $4 \cdot 6$ & 0.89 & 27 (3) \\
\hline 13 & 84.9 & & & 1 (1) \\
\hline 14 & 89.8 & $3 \cdot 3$ & 0.64 & $26(3)$ \\
\hline 15 & 92.6 & & & $1(1)$ \\
\hline 16 & $104 \cdot 3$ & & & $1(1)$ \\
\hline 17 & 109 & 0.6 & 0.3 & $3(3)$ \\
\hline 18 & 110 & $3 \cdot 5$ & 0.67 & 27 (3) \\
\hline 19 & 131 & & & 1 (1) \\
\hline 20 & 132 & $3 \cdot 5$ & 0.7 & 27 (3) \\
\hline 21 & 134 & $4 \cdot 3$ & 1.2 & $12(3)$ \\
\hline 22 & 147 & 3.8 & 0.72 & 27 (3) \\
\hline 23 & 159 & & & 1 (1) \\
\hline 24 & 175 & $3 \cdot 2$ & 0.82 & $15(3)$ \\
\hline 25 & 193 & $5 \cdot 2$ & 1.0 & 27 (3) \\
\hline 26 & 225 & 5.7 & $1 \cdot 1$ & 27 (3) \\
\hline 27 & 242 & & & 1 (1) \\
\hline 28 & 251 & & & $1(1)$ \\
\hline 29 & 267 & 4.8 & 0.96 & $25(3)$ \\
\hline 30 & 293 & 2.8 & 2 & $2(1)$ \\
\hline 31 & 376 & 10.9 & $2 \cdot 2$ & $24(3)$ \\
\hline
\end{tabular}




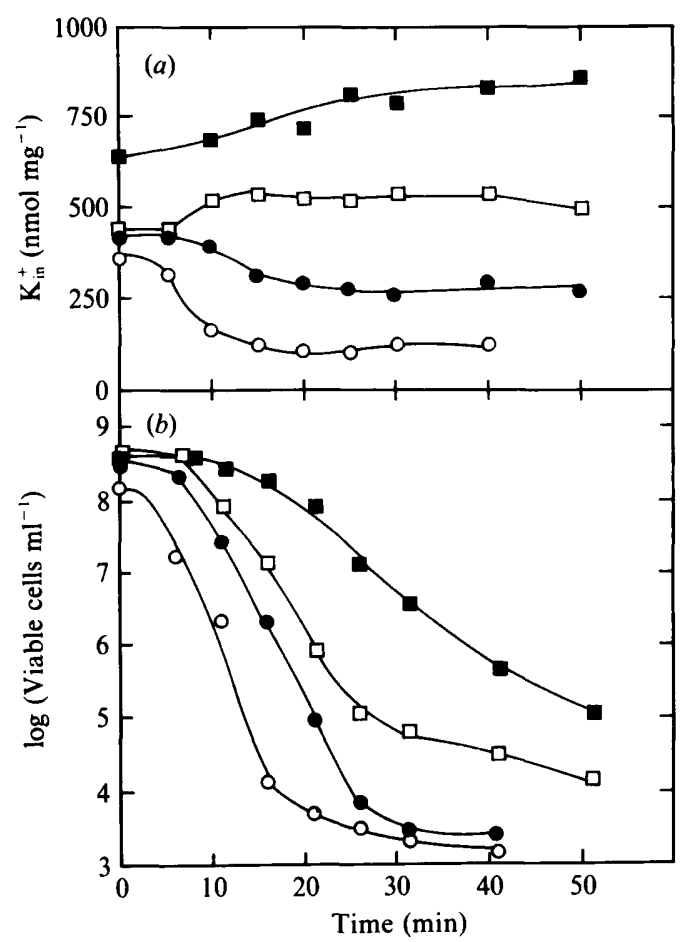

Fig. 3. $\mathrm{K}^{+}$content $(a)$ and viability $(b)$ of cells treated with streptomycin at different $\mathrm{K}^{+}$concentrations. Cells of $E$. coli TK 1110 were grown at the following $\mathrm{K}^{+}$concentrations: $0.5 \mathrm{~mm}(\mathrm{O}) ; 10 \mathrm{mM}$ $(\bullet) ; 30 \mathrm{~mm}(\square)$ and $115 \mathrm{~mm}(\square)$. Streptomycin $\left(50 \mu \mathrm{g} \mathrm{ml}^{-1}\right)$ was added at zero time. The $\mathrm{K}^{+}$content of the cells and number of viable cells of the suspension were determined as a function of time.

\section{Permeability changes for other ions}

Under the conditions where the cells lost $\mathrm{K}^{+}$, they took up $20 \%$ more $\mathrm{Na}^{+}$than they lost $\mathrm{K}^{+}$(Fig. $5 a$ ). Thus, streptomycin not only affects the transmembrane concentration gradient of $\mathrm{K}^{+}$and $\mathrm{Rb}^{+}$, but also that of another inorganic cation. In the experiment of Fig. 5(a), part of the $\mathrm{Na}^{+}$taken up in excess of $\mathrm{K}^{+}$was electrically compensated for by the efflux of $\mathrm{H}^{+}$, since the internal $\mathrm{pH}$ of the cells increased by $0 \cdot 15$ units (Fig. $5 b$ ). Sodium was not required for $\mathrm{K}^{+}$loss, since streptomycin-treated cells grown in the absence of $\mathrm{Na}^{+}$lost $\mathrm{K}^{+}$with a time course and to an extent similar to those of cells grown in the presence of $\mathrm{Na}^{+}$(Fig. $5 c, e$ ). Cells grown in the absence of $\mathrm{Na}^{+}$did not exchange $\mathrm{K}^{+}$for $\mathrm{H}^{+}$after streptomycin treatment, since the internal $\mathrm{pH}$ of these cells increased rather than decreased (Fig. 5d) This indicates that under these conditions the uptake of unidentified cations (possibly choline) or the exit of unidentified anions accompanies $\mathrm{K}^{+}$loss. Omission of choline and $\mathrm{Na}^{+}$from the medium led to a slightly different behaviour: $\mathrm{K}^{+}$loss became transient (Fig. 5e) and the internal $\mathrm{pH}$ of the treated cells was only initially

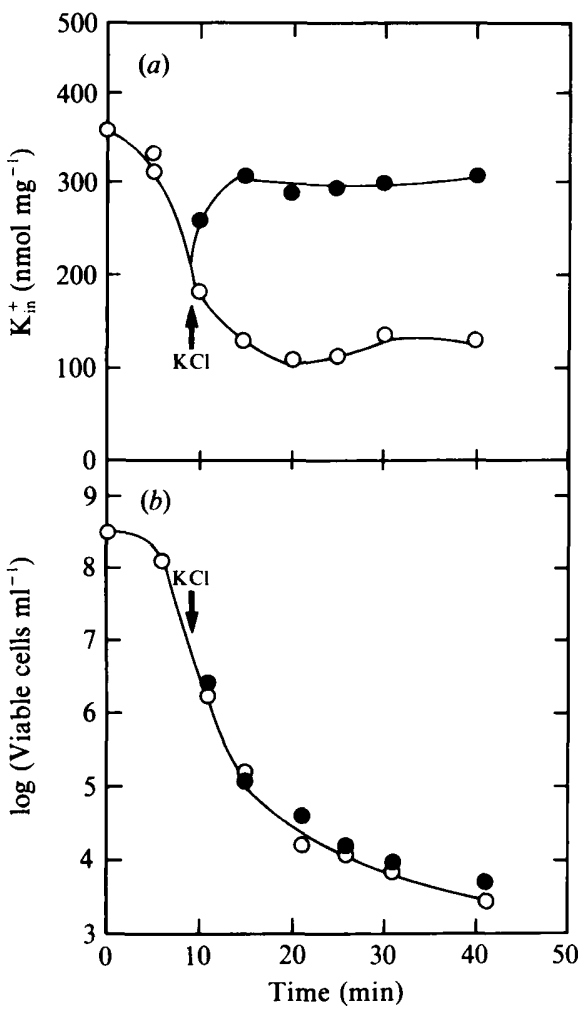

Fig. 4. The addition of an excess of $\mathrm{K}^{+}$to cells treated with streptomycin reverses $\mathrm{K}^{+}$loss $(a)$ but does not affect the rate with which cells lose their viability $(b)$. Two cultures of $E$. coli TK 1110 were grown in $\mathrm{K0} .5$ medium. At zero time $50 \mu \mathrm{g}$ streptomycin $\mathrm{ml}^{-1}$ was added to the two cell suspensions. At $t=9 \mathrm{~min}$ one culture received $10 \mathrm{mM}-\mathrm{KCl}(\bullet)$. The second culture served as the control (O). The $\mathrm{K}^{+}$ content of the cells and the number of viable cells were determined as a function of time.

higher than that of control cells (Fig. $5 f$ ). We will return to the phenomenon of transient $\mathrm{K}^{+}$loss below.

\section{Membrane potential}

The effects of streptomycin on cell membrane permeability are not large since streptomycin-treated cells still maintained substantial concentration gradients of $\mathrm{K}^{+}\left(\mathrm{Rb}^{+}\right)$and $\mathrm{H}^{+}$across their cytoplasmic membranes (Figs 1-5). To obtain more information on this point we measured the membrane potential of cells of strain AS-1, in which this potential can be measured without pretreatment with EDTA (Hirota et al., 1981). Remarkably, streptomycin caused hyperpolarization during the period that the cells lost $\mathrm{K}^{+}$(Fig. 6). This effect may be partially due to the inhibition of protein synthesis by streptomycin since chloramphenicol, added at a concentration at which it blocks protein synthesis completely, caused an even larger hyperpolarization (Fig. 6a). This 
Table 3. NheI restriction fragment fingerprint patterns for strains of serogroup A, clonal group III

NheI-generated fingerprint patterns of 26 strains with the $S f i$ fingerprint pattern characteristic of clonal group III were analysed. Each band was measured and assigned a band number on the basis of the data presented in Table 2 . The presence of a band in a given strain is indiated with a 1 , its absence with a 0 .

Band number

\begin{tabular}{|c|c|c|c|c|c|c|c|c|c|c|c|c|c|c|c|c|c|c|c|c|c|c|c|c|c|c|c|c|c|c|c|}
\hline Strain & 1 & 2 & 3 & 4 & 5 & 6 & 7 & 8 & 9 & 10 & 11 & 12 & 13 & 14 & 15 & 16 & 17 & 18 & 19 & 20 & 21 & 22 & 23 & 24 & 25 & 26 & 27 & 28 & 29 & 30 & 31 \\
\hline 2009 & 1 & 1 & 0 & 1 & 1 & 0 & 0 & 0 & 1 & 1 & 1 & 1 & 0 & 0 & 0 & 0 & 1 & 1 & 0 & 1 & 0 & 1 & 0 & 1 & 1 & 1 & 0 & 0 & 1 & 0 & \\
\hline 2033 & 1 & 1 & 0 & 0 & 1 & 1 & 0 & 0 & 1 & 1 & 0 & 1 & 0 & 1 & 0 & 0 & c & 1 & 0 & 1 & 1 & 1 & 0 & 0 & 1 & 1 & 0 & 0 & 1 & 0 & \\
\hline 2034 & 1 & 1 & 0 & 0 & 1 & 1 & 0 & 0 & 1 & 1 & 0 & 1 & 0 & 1 & 0 & 0 & 0 & 1 & 0 & 1 & 1 & 1 & 0 & 0 & 1 & 1 & 0 & 0 & 1 & 0 & \\
\hline 2038 & 1 & 1 & 0 & $\mathbf{0}$ & 1 & 1 & 0 & 0 & 1 & 1 & 1 & 1 & 0 & 1 & 0 & 0 & 0 & 1 & $\mathbf{0}$ & 1 & 1 & 1 & 0 & 0 & 1 & 1 & 0 & 0 & 1 & 0 & 1 \\
\hline 2039 & 1 & 1 & 0 & 0 & 1 & 0 & 0 & 0 & 1 & 0 & 1 & 1 & 0 & 1 & 0 & 0 & 1 & 1 & 0 & 1 & 0 & 1 & 0 & 1 & 1 & 1 & 0 & 0 & 1 & 0 & 1 \\
\hline 2040 & 1 & 1 & 0 & 0 & 1 & 1 & 0 & 0 & 1 & 1 & 0 & 1 & 0 & 1 & 0 & 0 & 0 & 1 & 0 & 1 & 1 & 1 & 0 & 0 & 1 & 1 & 0 & 0 & 1 & 0 & \\
\hline 2041 & 1 & 0 & 0 & $\mathbf{0}$ & 1 & 1 & 0 & 0 & 1 & 1 & 1 & 1 & 0 & 1 & 0 & 0 & 0 & 1 & 0 & 1 & 1 & 1 & 0 & 0 & 1 & 1 & 0 & 0 & 1 & 0 & \\
\hline 2042 & 1 & 1 & 0 & 0 & 1 & 1 & 0 & 0 & 1 & 1 & 0 & 1 & 0 & 1 & 0 & 0 & 0 & 1 & 0 & 1 & 1 & 1 & 0 & 0 & 1 & 1 & 0 & 0 & 1 & 0 & \\
\hline 2183 & 1 & 1 & 0 & 0 & 1 & 0 & 0 & $\mathbf{0}$ & 1 & 1 & 1 & 1 & 0 & 1 & 0 & 0 & 0 & 1 & 0 & 1 & 0 & 1 & 0 & 1 & 1 & 1 & 0 & 0 & 1 & 0 & 1 \\
\hline 2184 & 1 & 1 & 1 & 0 & 1 & 0 & 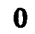 & 0 & 1 & 1 & 0 & 1 & 0 & 1 & 0 & 0 & 0 & 1 & 0 & 1 & 0 & 1 & 0 & 1 & 1 & 1 & 0 & 0 & 1 & 0 & \\
\hline 2185 & 1 & 1 & 0 & 0 & 1 & 0 & 0 & $\mathbf{0}$ & 1 & 1 & 0 & 1 & 0 & 1 & 0 & 0 & 0 & 1 & 0 & 1 & 0 & 1 & 0 & 1 & 1 & 1 & 0 & ( & 1 & 0 & \\
\hline 2186 & 1 & 1 & 0 & 0 & 1 & 0 & 0 & 0 & 1 & 1 & 0 & 1 & 0 & 1 & 0 & 0 & 0 & 1 & 0 & 1 & 0 & 1 & 0 & 1 & 1 & 1 & 0 & 0 & 1 & 0 & \\
\hline 2187 & 1 & 1 & 0 & 1 & 1 & $\mathbf{0}$ & 0 & 0 & 1 & 1 & 0 & 1 & 0 & 1 & 0 & 0 & 0 & 1 & 0 & 1 & 0 & 1 & 0 & 1 & 1 & 1 & 0 & 1 & 0 & 0 & \\
\hline 218 & 1 & 1 & 0 & 1 & 0 & $\mathbf{0}$ & 0 & 0 & 1 & 1 & 0 & 1 & 0 & 1 & 0 & 0 & 0 & 1 & 0 & 1 & 0 & 1 & 0 & 1 & 1 & 1 & 0 & 0 & 1 & 0 & \\
\hline 2189 & 1 & 1 & 0 & 0 & 1 & 0 & 1 & 0 & 1 & 1 & 0 & 1 & 0 & 1 & 0 & 0 & 1 & 1 & 1 & 1 & 0 & 1 & 0 & 1 & 1 & 1 & 1 & 0 & 1 & 0 & 0 \\
\hline 2221 & 1 & 1 & 0 & 0 & 1 & 0 & 0 & $\mathbf{0}$ & 1 & 1 & 0 & 1 & 0 & 1 & 0 & 0 & 0 & 1 & 0 & 1 & 0 & 1 & 0 & 1 & 1 & 1 & 0 & 0 & 1 & 0 & \\
\hline 2222 & 1 & 1 & 0 & 0 & 1 & 0 & 0 & 0 & 1 & 1 & 1 & 1 & 0 & 1 & 0 & 0 & 0 & 1 & 0 & 1 & 0 & 1 & 0 & 1 & 1 & 1 & 0 & 0 & 1 & 0 & \\
\hline 2223 & 1 & 1 & 0 & 1 & 0 & 0 & 0 & 0 & 1 & 1 & 1 & 1 & 1 & 1 & 0 & 1 & 0 & 1 & 0 & 1 & 0 & 1 & 1 & 1 & 1 & 1 & 0 & 0 & 0 & 1 & \\
\hline 222 & 1 & 1 & 0 & 0 & 1 & 0 & 0 & 0 & 1 & 1 & 1 & 1 & 0 & 1 & 0 & 0 & 0 & 1 & 0 & 1 & 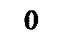 & 1 & 0 & 1 & 1 & 1 & 0 & ( & 1 & 0 & \\
\hline 2225 & 1 & 1 & 0 & $\mathbf{0}$ & 1 & 1 & 0 & 0 & 1 & 1 & 0 & 1 & 0 & 1 & 0 & 0 & 0 & 1 & 0 & 1 & 1 & 1 & 0 & 0 & 1 & 1 & 0 & 0 & 1 & 0 & \\
\hline 2226 & 1 & 1 & 0 & $\mathbf{0}$ & 1 & $\mathbf{0}$ & 0 & 0 & 1 & 1 & 0 & 1 & 0 & 1 & 0 & 0 & 0 & 1 & 0 & 1 & 0 & 1 & 0 & 1 & 1 & 1 & 0 & 0 & 1 & 0 & \\
\hline 222 & 1 & 1 & 0 & 0 & 1 & 1 & 0 & 0 & 1 & 1 & 0 & 1 & 0 & 1 & 0 & 0 & 0 & 1 & 0 & 1 & 1 & 1 & 0 & 0 & 1 & 1 & 0 & 0 & 1 & 0 & \\
\hline 222 & 1 & 1 & 0 & 0 & 1 & 1 & 0 & 0 & 1 & 1 & 0 & 1 & 0 & 1 & 0 & 0 & 0 & 1 & 0 & 1 & 1 & 1 & 0 & 0 & 1 & 1 & 0 & 0 & 1 & 0 & \\
\hline 2230 & 1 & 1 & 0 & 0 & 1 & 0 & 1 & 1 & 0 & 1 & 0 & 1 & 0 & 1 & 0 & 0 & 0 & 1 & 0 & 1 & 1 & 1 & 0 & 0 & 1 & 1 & 0 & 0 & 1 & 0 & \\
\hline 2233 & 1 & 1 & 0 & $\mathbf{0}$ & 1 & 0 & 0 & 0 & 1 & 1 & 1 & 1 & 0 & 1 & 1 & 0 & 0 & 1 & 0 & 1 & 0 & 1 & 0 & 1 & 1 & 1 & 0 & 0 & 1 & 1 & \\
\hline 2236 & 1 & 1 & 0 & 0 & 1 & 1 & 0 & 0 & 1 & 1 & 0 & 1 & 0 & 1 & 0 & 0 & 0 & 1 & 0 & 1 & 1 & 1 & 0 & 0 & 1 & 1 & 0 & 0 & 1 & 0 & 1 \\
\hline 2237 & 1 & 1 & 0 & 0 & 1 & 1 & 0 & 0 & 1 & 1 & 0 & 1 & 0 & 1 & 0 & 0 & 0 & 1 & 0 & 1 & 1 & 1 & 0 & 0 & 1 & 1 & 0 & 0 & 1 & 0 & 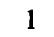 \\
\hline
\end{tabular}

chromosome. Thus, the relationships between strains with diverse fingerprints is difficult to assess solely from the number of shared bands. A phenogram such as that illustrated in Fig. 4 is therefore a guide to the interpretation of the fingerprint data rather than a true representation of phylogenetic relationships.

\section{Relationships between serogroup A strains with identical} Sfil fingerprints revealed by comparative analysis of NheI fingerprints

The strains included in the cluster analysis (Fig. 4) were isolated between 1937 and 1988 and were from various geographical locations, including Asia, North and South America, Europe and Africa. With the exception of strains 2223 (isolated in China in 1966) and 2189 (isolated in Brazil in 1976) these strains divided into two branches of the tree. One of these comprises only strains isolated in 1987/8 in Africa, Europe and America ('new wave pandemic'; Moore et al., 1989; Salih et al., 1990; Achtman et al., 1992), many of these strains have fingerprints that are identical, which is consistent with the rapid spread of this disease-causing clone. The other branch is more diverse, perhaps reflecting a more gradual spread of the disease caused by subgroup III meningococci during the 'old wave' pandemic. Some strains isolated in 1987 and 1988 cluster with the 'old wave' strains. It is possible that these strains were 'old wave' strains still present during the 'new wave' pandemic. The NheI fingerprint patterns appear to be stable over at least several decades and during geographical spread of the strains.

\section{Comparison of PFGE fingerprint data with clonal subgroups determined by $M L E E$}

There are a number of discrepancies between the PFGE fingerprint patterns and the subgroups determined by MLEE. These discrepancies presumably reflect differences in the nature of the data used by each technique. In the absence of a physical and genetical map of the meningococcal chromosome, it is not possible to compare these data directly. Discrepancies could be caused by differences between the chromosomal locations of the genes encoding the proteins used in MLEE and the NheI sites, or by changes in chromosome structure which did 


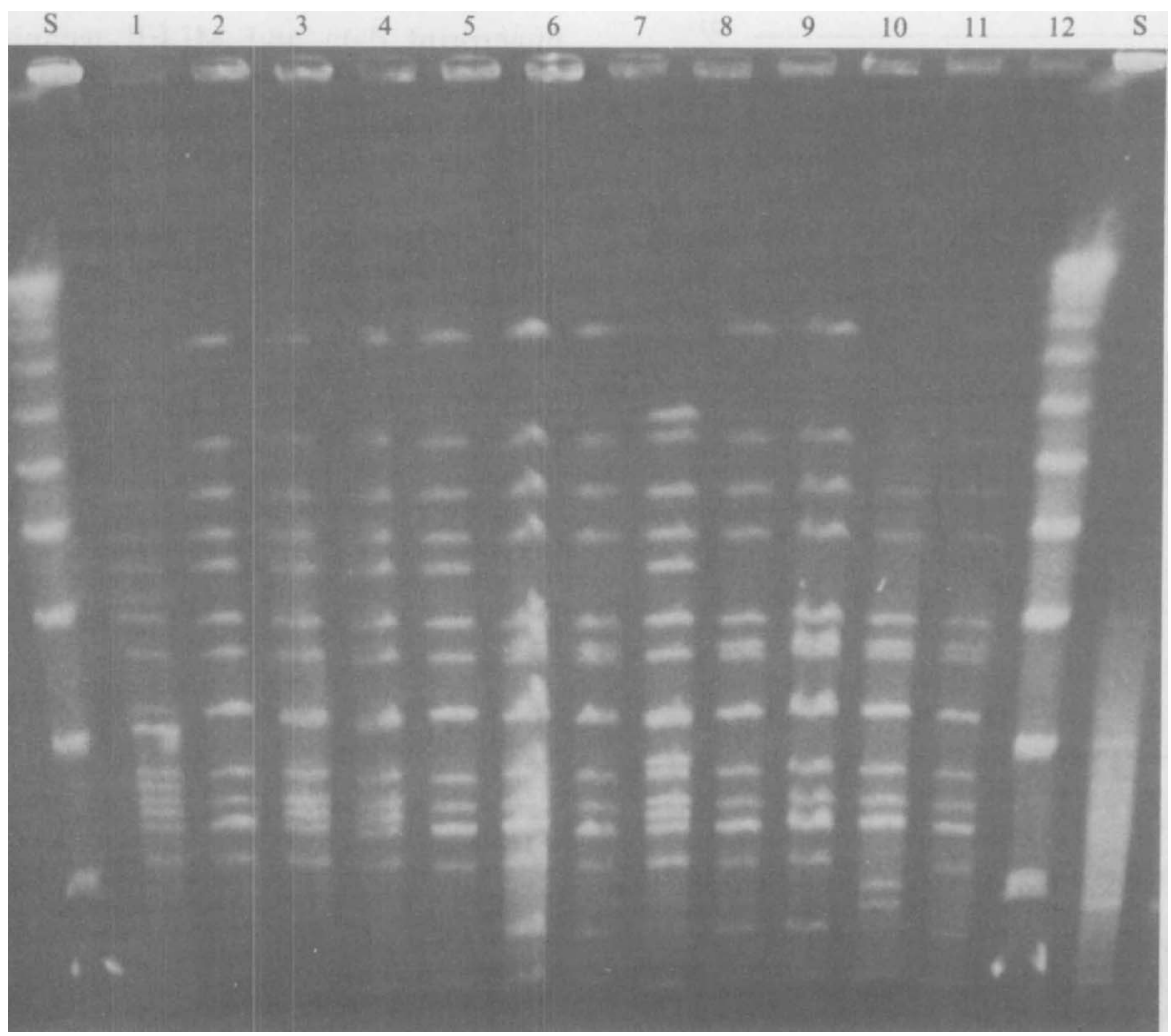

Fig. 3. NheI fingerprints of thirteen serogroup A strains belonging to clone III from various dates and geographical locations. Standards (S) as Fig. 1. Lane 1, strain 2223 (China, 1966); lane 2, strain 2226 (Norway, 1969); lane 3, strain 2224 (Sweden, 1973); lane 4, strain 2222 (Finland, 1975); lane 5, strain 2221 (China, 1987); lane 6, strain 2225 (UK, 1987); lane 7, strain 2237 (USA, 1987); lane 8, strain 2233 (Sweden, 1983); lane 9, strain 2227 (Chad, 1988); lane 10, strain 2228 (Chad, 1988); lane 11, strain 2230 (Sudan, 1987); lane 12, strain 2236 (Sudan, 1988).

not affect the phenotypic characters used in MLEE studies.

Strain 2009, which is subgroup IV-3 (strain M1027 in Olyhoek et al., 1987; M. Achtman, personal communication) on the basis of MLEE data, appears to be more closely related to the 'old wave' subgroup III-1 than to strain 2190 (subgroup IV-1) (Figs 1 and 2). It is difficult to explain this result, although it is possible that the chromosome structures of strains assigned to clone IV-3 are more closely related to those of strains of subgroup III-1 than to those of subgroup IV-1. Data from more strains assigned to subgroup IV is required to resolve this discrepancy.

Strain 2230 (isolated from Sudan in 1987, from the 'new wave' pandemic) differed in four bands (loss of bands 6 and 9 and gain of bands 7 and 8 ) from the other 'new wave' pandemic strains, and hence appeared to be quite distinct from, although still related to, these strains. These band differences could be explained by a single inversion that changed the relative position of only one nucleotide site if bands 6 and 9 are contiguous. Chromosome rearrangement events could change the fingerprint pattern with relatively little effect on the MLEE type; this type of event could explain the relatively large difference between the fingerprint of strain 2223 and other III-1 strains.

Strains 2188 and 2189 are both subgroup III-4, but have different fingerprint patterns. The chromosome of strain 2189 is apparently larger $(2 \cdot 1 \mathrm{Mbp})$ than that of strains $2183-2188(1.94-1.96 \mathrm{Mbp})$. It is possible that this difference in fingerprint pattern is caused by the presence of a large episome or a genetical element such as a prophage integrated into the chromosome introducing two extra NheI sites into the largest NheI fragment. In the case of strains 2185 (ET-38, subgroup III-1) and 2186 (ET-39, subgroup III-2), which had the same fingerprint pattern, the fingerprint data appeared to be less discriminatory than the MLEE data, although on the basis of their epidemiology (both strains were isolated in Finland in the 1970s) the strains could be closely related.

The present work demonstrates that PFGE fingerprints can be used to identify relationships among clinical isolates of meningococci with two restriction endonucleases (SfiI and NheI). The NheI fingerprints 


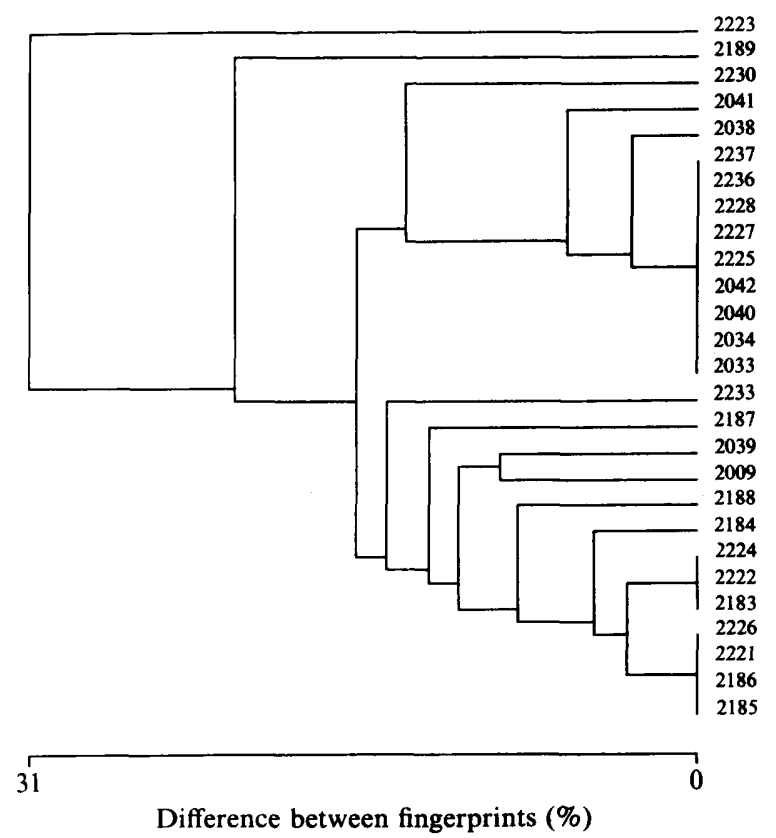

Fig. 4. Phenogram illustrating differences between the NheI fingerprints of 27 serogroup A, clone III meningococcal strains. The percentage similarity between fingerprints was calculated on the basis of the number of bands shared between each possible pair of fingerprints. All the strains represented in this figure had identical SfiI fingerprint patterns.

were capable of greater resolution and distinguished 'old wave' and 'new wave' strains belonging to subgroup III-1. Clonal analysis with PFGE fingerprint data has a number of advantages. The fingerprint is a characteristic of a particular strain which enables the analysis of the whole chromosome of the target organism. The patterns depend on many independent chromosomal loci, the number of which can be altered by the appropriate choice of restriction endonuclease. Inclusion of data from several different endonucleases also improves the coverage of the chromosome, and examines the possibility that the data are adversely affected by factors such as site-specific methylation in the chromosome. The patterns, which are stable for a number of passages in vitro and probably over many years in culture collections, are readily recognized and the fragment sizes may be compared with those obtained for other isolates to establish the relationships within clonal subgroups. The fingerprint patterns are independent of variable antigens, the genes of which may change at a faster rate than the rest of the chromosome. The development of DNA probes to particular genes will enable the relation of fingerprint data directly to chromosome maps, giving a more precise estimation of the chromosome structures being analysed. Finally, the PFGE technique is relatively simple and rapid. A more detailed analysis is being undertaken to compare the results obtained by PFGE fingerprint data and MLEE techniques. The PFGE approach is particularly useful for the analysis of closely related strains, such as those isolated from a single outbreak of the disease.

The Pulsaphor apparatus was provided by the National Meningitis Trust. The bacterial strains were kindly provided by Dr M. Achtman of the Max-Planck Institut für Molekulare Genetik, Berlin, FRG and Dr D. M. Jones of the Public Health Laboratory Service, Withington Hospital, Manchester. We also thank Dr M. Achtman for encouragement, advice, and the provision of information and strains prior to publication, and Dr Wang Jian fu for valuable comments on the manuscript. We are grateful to Dr I. M. Feavers for discussions and comments on the manuscript, Mr A. Heath for assistance with the construction of phenograms and advice on the statistical analysis of fingerprint patterns, to Dr M. J. Corbel and Dr G. C. Schild for critically reading the manuscript and to $\mathrm{Mr} \mathrm{A}$. Davis for photographical work.

\section{References}

ACHTman, M. (1990). Molecular epidemiology of epidemic bacterial meningitis. Reviews in Medical Microbiology 1, 29-38.

achtman, M., Kusbcex, B., Morelli, G., Eickmann, K., Wang, J., Crowb, B., Wall, R. A., Hassan-King, M., Moore, P. S. \& ZOLLINGER, W. (1992). A comparison of the variable antigens expressed by clone IV-1 and subgroup III of Neisseria meningitidis. Journal of Infectious Diseases 165, in the Press.

ARbeit, R. D., ARThur, M., DunN, R., Kim, C., Selander, R. K. \& GolDSTEIN, R. (1990). Resolution of recent evolutionary divergence among Escherichia coli from related lineages: the application of pulsed field electrophoresis to molecular epidemiology. Journal of Infectious Diseases 161, 230-235.

Bjorvatn, B., Lund, V., Kristiansen, B.-E., Korsnes, L., SPANNe, O. \& LINDQVIST, B. (1984). Applications of restriction endonuclease fingerprinting of chromosomal DNA of Neisseria meningitidis. Journal of Clinical Microbiology 19, 763-765.

Carle, G. F., Frank, M. \& Olson, M. V. (1986). Electrophoretic separations of large DNA molecules by periodic inversion of the electric field. Science 232, 65-68.

Cartwright, K. A. V., Stuart, J. M. \& Noah, N. D. (1986). An outbreak of meningococcal disease in Gloucestershire. Lancet ii, 558-561.

Caugant, D. A., Frøholm, L. I., Bøvre, K., holten, E., Frasch, C. E., Mocca, L. F., Zollinger, W. D. \& Selander, R. K. (1986). Intercontinental spread of a genetically distinctive complex of clones of Neisseria meningitidis causing epidemic disease. Proceedings of the National Academy of Sciences of the United States of America 83, 4927-4931.

Caugant, D. A., Mocca, L. F., Frasch, C. E., Froholm, L. O., ZOLLINGER, W. D. \& SELANDER, R. K. (1987). Genetic structure of Neisseria meningitidis populations in relation to serogroup, serotype, and outer membrane protein pattern. Journal of Bacteriology 169, 2781-2792.

Caugant, D. A., Bol, P., Høiby, E. A., Zanen, H. C. \& Frøholm, L. O. (1990). Clones of serogroup B Neisseria meningitidis causing systemic disease in the Netherlands, 1958-1986. Journal of Infectious Diseases 162, 867-874.

Crowe, B. A., Abdillahi, H., Poolman, J. T. \& Achtman, M. (1988). Correlation of serological typing and clonal typing methods for Neisseria meningitidis sero-group A. Journal of Medical Microbiology 26, 183-187.

Crowe, B. A., Wall, R. A., Kusecek, B., Nbumann, B., Olyhoek, T., Abdillahi, H., Hassan-King, M., Greenwood, B. M., Poolman, J. T. \& ACHTMAN, M. (1989). Clonal and variable properties of Neisseria meningitidis isolated from cases and carriers during and after an epidemic in The Gambia, West Africa. Journal of Infectious Diseases 159, 686-700. 
DeVoe, I. W. (1982). The Meningococcus and mechanisms of pathogenicity. Microbiological Reviews 46, 162-190.

Fox, A. J., Jones, D. M., Gray, S. J., Caugant, D. A. \& Saunders, N. A. (1991). An epidemiologically valuable typing method for Neisseria meningitidis by analysis of restriction fragment length polymorphisms. Journal of Medical Microbiology 34, 265-270.

Frasch, C. E. (1989). Vaccines for prevention of meningococcal disease. Clinical Microbiological Reviews 2, S134-S138.

Frasch, C. E., Zahradnix, J. M., Wang, L. Y., Mocca, L. F. \& TSaI, C.-M. (1988). Antibody response of adults to an aluminium hydroxide-adsorbed Neisseria meningitidis serotype $2 \mathrm{~b}$ protein-group B polysaccharide vaccine. Journal of Infectious Diseases 158, 710-718.

JoNeS, D. M. \& SUTCLIFFe, E. M. (1990). Group A meningococcal disease in England associated with the Haj. Journal of Infection 21 , 21-25.

Maniatis, T., Fritsch, E. F. \& SAmbroox, J. (1982). Molecular Cloning: a Laboratory Manual. Cold Spring Harbor, NY: Cold Spring Harbor Laboratory Press.

Moore, P. S., ReeVes, M. W., Schwartz, B., Gellin, B. G. \& BROOME, C. V. (1989). Intercontinental spread of an epidemic group A Neisseria meningitidis strain. Lancet ii, 260-262.

Ol YHOEK, T., CROWE, B. A. \& ACHTMAN, M. (1987). Clonal population structure of Neisseria meningitidis serogroup A isolated from epidemics and pandemics between 1915 and 1983. Reviews of Infectious Diseases 9, 665-682.

Olyhozk, T., Crowe, B. A., Wall, R. A. \& Achtman, M. (1988), Comparison of clonal analysis and DNA restriction analysis for typing of Neisseria meningitidis. Microbial Pathogenesis 4, 45-51.

Peltola, H. (1983). Meningococcal disease: still with us. Reviews of Infectious Diseases 5, 71-91.
Reingold, A. L., Broome, C. V., Hightower, A. W., Ajello, G. W., Bolan, G. A., Adamsbaum, C., Jones, E. E., Phillips, C., TiEndRebeogo, H. \& YADA, A. (1985). Age-specific differences in duration of clinical protection after vaccination with meningococcal polysaccharide A vaccine. Lancet ii, 114-118.

Salih, M. A., Danielsson, D., Backman, A., Caugant, D. A., Achtman, M. \& OlcÉn, P. (1990). Characterisation of epidemic and nonepidemic Neisseria meningitidis serogroup A strains from Sudan and Sweden. Journal of Clinical Microbiology 28, 1711-1719.

SCHWARTZ, B., MOORE, P. S. \& BROOME, C. V. (1989). Global epidemiology of Meningococcal disease. Clinical Microbiology Reviews 2, S118-S124.

SchwarTZ, D. C. \& CantoR, C. R. (1984). Separation of yeast chromosome-sized DNAs by pulsed field gradient gel electrophoresis. Cell 37, 67-75.

Selander, R. K., Caugant, D. A., Ochman, H., Musser, J. M., GiLmour, M. N. \& WhitTaM, T. S. (1986). Methods of multilocus enzyme electrophoresis for bacterial population genetics and systematics. Applied and Environmental Microbiology 51, 873-884.

Selander, R. K., Musser, J. M., Caugant, D. A., Gilmour, M. N. \& WhITTAM, T. S. (1987). Population genetics of pathogenic bacteria. Microbial Pathogenesis 3, 1-7.

SMith, C. L., Econome, J. G., SChUtt, A., KLCo, S. \& CaNtor, C. R. (1987). Physical map of the Escherichia coli $\mathrm{K} 12$ genome. Science 236, 1448-1453.

SOKAL, R. R. \& MiChENER, C. D. (1958). A statistical method for evaluating systematic relationships. University of Kansas Science Bulletin 28, 1409-1438.

Stull, T. L., LiPUMA, J. J. \& EdLIND, T. D. (1988). A broad spectrum probe for molecular epidemiology of bacteria: ribosomal RNA. Journal of Infectious Diseases 157, 280-286. 